\title{
A comparative analysis of advanced techniques for skin reconstruction with autologous keratinocyte culture in severely burned children: own experience
}

\author{
Anna Chrapusta ${ }^{1}$, Michał B. Nessler ${ }^{1}$, Justyna Drukala², Marzenna Bartoszewicz ${ }^{3}$, Ryszard Mądry ${ }^{4}$ \\ ${ }^{1}$ Malopolska Center for Burn and Plastic Surgery, Ludwik Rydygier Memorial Specialized Hospital, Krakow, Poland \\ Head of Center: Anna Chrapusta MD, PhD \\ 'Laboratory of Cell and Tissue Engineering, Department of Cell Biology, Faculty of Biochemistry, Biophysics and Biotechnology, \\ Jagiellonian University, Krakow, Poland \\ Head of Department: Prof. Zbigniew Madeja PhD, DSc \\ ${ }^{3}$ Department of Microbiology, Medical University of Wroclaw, Poland \\ Head of Department: Assoc. Prof. Grażyna Gościniak PhD \\ ${ }^{4}$ The Eastern Center for Burn and Reconstructive Surgery, Łęczna, Poland \\ Head of Center: Prof. Jerzy Strużyna MD, PhD
}

\begin{abstract}
Introduction: The local treatment in burns larger than $50 \%$ of total body surface area is still the great challenge for surgeons.

Aim: This paper presents a review of different solutions for deep burn wound healing in children and the early outcomes of treatment with combined autologous cell culture technique.

Material and methods: For this study, 20 children aged between 4 and 12 years with $55-65 \%$ of TBSA III grade burn injury were analyzed. A skin sample, $1 \mathrm{~cm} \times 1 \mathrm{~cm}$ in size, for keratinocyte cultivation, was taken on the day of the burn. After necrotic tissue excision, the covering of the burned area with an isolated meshed skin graft was carried out between day 4 and 7. After 7 days of keratinocyte cultivation, the mentioned areas were covered with cells from the culture. We divided the burned regions, according to the way of wound closure, into 3 groups each consisting of 15 treated regions of the body. We used meshed split thickness skin grafts (SSG group), cultured autologous keratinocytes (CAC group), and both techniques applied in one stage (SSG + CAC group).

Results: In the SSG group, the mean time for complete closure of wounds was 12.7 days. Wounds treated with CAC only needed a non-significantly longer time to heal -14.2 days $(p=0.056)$ when compared to SSG. The shortest time to heal was observed in the group treated with SSG + CAC -8.5 days, and it was significantly shorter when compared to the SSG and CAC groups ( $p<0.001$ ).

Conclusions: This study suggests that cultured keratinocytes obtained after short-time multiplication, combined with meshed autologous split thickness skin grafts, constitute the optimal wound closure in burned children.
\end{abstract}

Key words: burn, skin graft, meshed graft, skin cell culture.

\section{Introduction}

Skin is the largest organ of the human body and plays multiple functions in maintaining the homeostasis of the human body. The most significant role is protection from the external environment. The loss of this barrier requires a closure of the wounded surface. The surgical problems with skin defect closure depend mainly on the location and total size of the skin defect [1-3]. It is well known that there has been no full skin substitute avail- able to date. Skin replacement has been a challenge for surgeons and scientists since the introduction of skin grafts by Reverdin in $1871[1,4]$. This achievement and the development of the meshed skin graft technique are still the basic principles in burn management. Split-thickness skin autograft (STSG) is the gold standard in the treatment of large full-thickness burn wounds. The development of permanent and temporary skin substitutes has been particularly beneficial for patients with severe

Address for correspondence: Anna Chrapusta MD, PhD, Malopolska Center for Burn and Plastic Surgery, Ludwik Rydygier Memorial Specialized Hospital, os. Złotej jesieni 1, 31-826 Krakow, Poland, phone: +48 602342 354, e-mail: anna.chrapusta@gmail.com Received: 12.02.2014, accepted: 14.03.2014. 
burns of a large burn surface [2, 5]. In the case of burns involving more than $50 \%$ of the total body surface area, the availability of donor skin is limited. In such cases, there are not enough skin resources in the patient's own body that would allow for overall recovery and healing.

The rapid expansion of tissue engineering has given an opportunity for the development of cell culture technology. Among these techniques, primary cell culture has recently become the most common in burn treatment. Multiplication of isolated keratinocytes was introduced by Rheinwald and Green in 1975 [4]. Autologous keratinocyte culture was applied in the treatment of burns in 1981 [6]. The original technique was based on the fast multiplying of a large number of epithelial cells. The intervals for cell-multiplication were shorter than $24 \mathrm{~h}$ [4]. Keratinocytes were cultured in clonal cell densities on a "feeder-layer" of lethally irradiated mouse fibroblasts, and with the use of trypsin. Then, cells were taken to the secondary culture. This process has created the growth of isolated colonies of epithelial cells, which are expanded into broad sheets of undifferentiated epithelial cells [6]. This basic method has been modified several times. Outstanding research efforts led to the formulation of almost perfect, commercially available, media. Many cell laboratories and bioreactors are used to improve the proliferation of cultured keratinocytes [4, 7, 8]. This makes it possible to obtain a large number of cells in a short time. It also makes it possible to accelerate the healing process, minimize the number of surgical procedures and decrease the time of recovery of severely burn-injured patients. In 1994, an autologous cell suspension (Cell Spray) was introduced [9]. It enabled the application of cultured cells into the wound via aerosol, directly on the surface of the burn wound, after the removal of necrotic tissue. This technique was also used for the donor graft areas [9].

The first report of cell suspension was prepared by von Manglodt in 1895, who treated chronic wounds with the seeding of epithelial cells, harvested by scraping the patient's forearm [4]. The common method at this time was the technique of the Reverdin skin graft. In a comparison of both of the above methods, it was found that the individual cells or cell clusters would better attach to the wound bed, than to a piece of grafted skin [4]. Such results were especially promising at that time. Pels-Leudsen introduced a new technique, with the application of epithelial cell serum and blood suspension, with the use of a syringe $[4,10]$. Consecutively, the goal of researchers was to discover factors that could improve the multiplication of cells in vitro.

Another approach to the treatment of burns was to combine the allogeneic keratinocyte culture and acellular fully sterilized xenodermis prepared from a pig's dermis [11]. In the case of severe burns in pediatric patients, in order to improve wound healing time and to reduce the liability of post-burn contractures, Fujimori covered the burn area in a two-stage operation. The first stage involved the use of autologous keratinocytes and was followed by the second stage performed 5 to 12 days later. In the second stage, the whole area was also covered with an extra thin autologous split-thickness skin graft [12].

The next aim was to improve reepithelialization after the application of keratinocytes to the wound bed. One of the factors which improved reepithelialization was the use of the fibrin [7]. Studies have shown that the relative percentage of following cells including holoclones, meroclones, and paraclones of keratinocytes is maintained, when they are cultivated on fibrin [4]. It was also proved that fibrin does not have a negative influence to the stem cell. El Ghalbzouri's experiments had proved that the cultivation of human keratinocytes on the collagen matrix without the presence of fibroblasts allow for the formation of only three to four cell layers. Cultures with the presence of fibroblasts produce far better results. Not only the number of fibroblasts, but also their functional state, including levels of integrin- $\alpha 2$ and 3 and integrin- $\beta 1$ are a key factor in epidermal morphogenesis $[8,13]$. According to the literature on the subject, from the financial point of view, the use of keratinocyte-fibrin-suspension (KFS) allowed for a significant reduction in the cell culturing costs. What is more, it helps to eliminate the problem with cultured cells handling and transportation [4].

Further attempts to modify the techniques of burn wound treatment were the combination of skin grafts and cell suspension. The trials of Australian authors (i.e. Fiona Wood) on various methods of the harvesting and applying of the cell suspension, resulted in a unique achievement - the ReCell ${ }^{\circledR}$ technique that offers a possible solution to help expedient wound closure [9]. The ReCell ${ }^{\circledR}$ kit (Avita Medical, United Kingdom) is a medical device that assists plastic, cosmetic, dermatology and burn surgeons in repairing a wide range of skin defects. It is an innovative medical tool that is used for harvesting autologous skin cells. ReCell囚 enables the exploitation of a thin split-thickness biopsy, which is taken at the time of the procedure. The skin specimens that are processed into an immediate cell population are delivered directly onto the wound surface using a spray syringe. ReCell® enables the application of keratinocytes, melanocytes, fibroblasts and Langerhans cells harvested from the epidermal-dermal junction. It allows the promotion of further effective wound healing. The important benefit of ReCell ${ }^{\circledR}$ is its potential for use by a single clinician, without the employment of specialized laboratory staff [9].

Another method was the application of autologous cultured keratinocytes in suspension additionally to the skin allografts (allogeneic split thickness skin grafts). In this technique, the allograft is first used as an initial wound bed preparation. Subsequently, the wound is closed with the cultured, autologous cells, together with the use of a meshed split-thickness allograft as an overlay. After 12-14 days, the immunogenic reaction of rejection is observed. Clinical observations show that 
permanent wound closure was achieved during the time when the epithelial parts of the allografts have been rejected $[14,15]$.

For this reason, the authors have compared the course of treatment using three different methods. In the first group, wounds were covered with meshed split-thickness skin graft. In the second group, the authors used autologous cell cultures. In the third group, wounds were covered with a combination of both techniques.

\section{Aim}

Having done the above review of the current techniques taking place within clinical practice, and despite the limited self-experience in the application of various advanced biotechnological methods, the authors as sessed the early outcomes of cases treated with two different application types of autologous cell culture when compared with conventional split-thickness skin grafting.

\section{Material and methods}

We analyzed 20 children with full-thickness skin burn (III grade), aged between 4 and 12 years. The analyzed group consisted of 8 girls and 12 boys. The burn size embraced $55-65 \%$ of the total body surface area (TBSA).

All the children had been deeply burned by flames. Seven patients had burns of the thorax, abdomen and upper limbs. Four patients had burns of the trunk and both shoulders. Another 2 patients had upper limbs, thorax, neck and face affected. Other two cases had full-thickness skin burns of the lower limbs, buttocks and lumbar region. One patient had a burn of the upper left limb with the left shoulder, neck, face, the left side of the thorax, abdomen and the perineum. Two children had burns involving the neck, upper limbs, thorax, abdomen, and the frontal part of both thighs. One of the girls had additionally a burned face. The last patient had third degree flame burns of the upper and lower limbs, the neck, shoulders and partially the thorax.

All patients were treated surgically with early necrotic tissue excision. The necrectomy was completed within day 3 and day 5 following the burn accident. The skin graft was done between day 4 and day 8 of the post burn injury and the keratinocyte application between day 7 and day 8. One of the three techniques had been used for wound closure: split-thickness skin graft, autologous keratinocyte culture, and both techniques in one stage. The tissue defect was covered with split tissue skin grafts taken with Padgett electro-dermatome. Graft thickness varied from 0.012 to 0.014 inches. The grafts were meshed at a $3: 1$ expansion ratio before application, to minimize the surface of the donor area. In the largest burns, we decided to use keratinocyte culture. The specimens of the skin for cell culture were taken immediately after admission to the hospital on the day of the burns. We took the skin sample of a size of approximately $1 \mathrm{~cm}$ $\times 1 \mathrm{~cm}$, using the blade and local anesthesia. The autologous keratinocytes for definite coverage of an area of $600 \mathrm{~cm}^{2}$ were cultured for 7 days. Then the application of the cultured cells with Tissucol ${ }^{\circledR}$ Kit (Baxter AG), a fibrin glue, was performed.

Patients with the largest burn area had been treated using two of the three described techniques simultaneously. It means that one area was grafted with a split-thickness skin meshed graft and the second was, at the same time, closed by keratinocytes or a skin graft and keratinocytes.

All the compared wounds started to close from the $4^{\text {th }}$ to $8^{\text {th }}$ day after the burn. All the compared areas were similar in size, in shape and as regards location. The wounds were located on the trunk, the upper or lower extremities. The total burn areas were comparable between the three groups. The patients underwent the same system of control after surgery. All the particular comparable areas were comprehensively treated using only a single method.

The wounds in the analyzed groups of patients were divided into 3 groups, according to their clinical treatment. Each group consisted of 15 burned areas. The size of the compared areas was approximately from $225 \mathrm{~cm}^{2}$ to $300 \mathrm{~cm}^{2}$. The first group (SSG) embraced 15 burn wounds treated conventionally with a split-thickness skin graft, meshed at a ratio of $3: 1$, applied with maximal graft expansion. The second group consisted of 15 regions covered only with cultured autologous cells (CAC). The third group comprised 15 burn wounds managed with both methods (SSG + CAC). Meshed split-thickness skin grafts $(3: 1)$ had been applied. The pattern of the meshed grafts was applied to the wound with a similar expansion in both groups (SSG, SSG + CAC). In the same stage of the procedure, in the third group, the grafts were supported by the application of autologous keratinocyte culture into the network of the meshed skin. We have compared the time of burn wound healing in the above groups. All the children were in a similar general condition during this study, without any additional health disturbances that could have impaired or altered the healing process.

The comparable burn wounds had a similar location and size. No local infection in the comparable wounds occurred. Wounds with infection were excluded from the analysis as a result of the presence of a known factor that directly impairs healing.

\section{Statistical analysis}

The statistical analysis was performed using SPSS ${ }^{\circledR}$ 18 software. To compare the time needed to heal, we used a one-way ANOVA test with LSD post-hoc multiple comparisons. 
Table 1. Healing time characteristics in the analysed groups

\begin{tabular}{lccc}
\hline General data & SSG & CAC & SSG + CAC \\
\hline Number of wounds treated & 15 & 15 & 15 \\
\hline Shortest time of wound healing* [days] & 8 & 13 & 7 \\
\hline Longest time of wound healing* [days] $^{*}$ & 16 & 17 & 11 \\
\hline
\end{tabular}

*The time was calculated from the day of the application of the selected method

\section{Results}

In this study, the time for the healing of burn wounds following different surgical treatment is described in Table 1 and Figure 1. In the SSG group, the mean time for the complete closure of the wounds, after grafting with split-thickness skin graft meshed at a ratio of $3: 1$, was approximately 12.7 days. In group II, the period between cell application and the safe final removal of the dressing and healing time, was approximately 14.2 days. This was non-significantly longer in the SSG group $(p=0.056)$. Earlier healing without dressing is possible but unsafe, when the matter relates to small non-cooperative children.

In the last group (SSG + CAC), the authors used a "modified sandwich technique", which means that the coverage of the burn wound bed with a mesh split-thickness skin graft was supported by the application of autologous keratinocyte culture into the pattern/network of the meshed skin. The average time when patients required the dressing-change (which in this group equals wound healing time) was approximately 8.5 days (from mesh-grafting and keratinocyte application to the clinical closure of the covered area) (Figures 2 and 3). In this group, the healing time was the shortest and the mean time was 8.5 days. This result was significantly shorter when compared to SSG only $(p<0.000)$ and CAC only $(p<0.000)$.

\section{Discussion}

According to the observation of the healing of the burned wound treated with the "modified sandwich

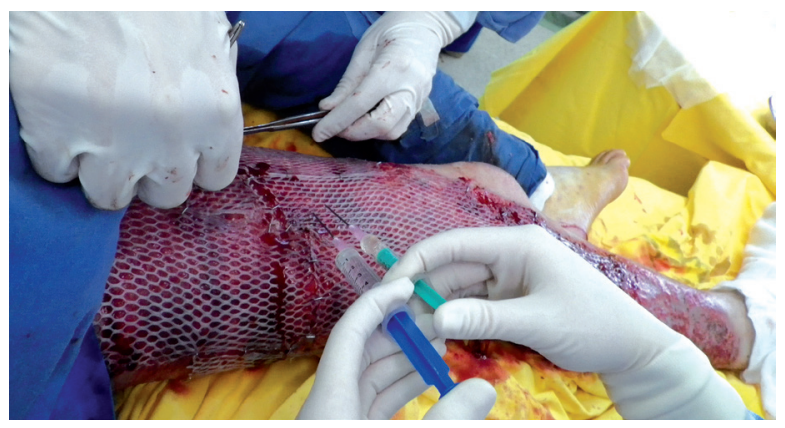

Figure 2. The application of the meshed split thickness skin graft and cultured autologous keratinocytes to a III degree flame burn wound of the lower limb

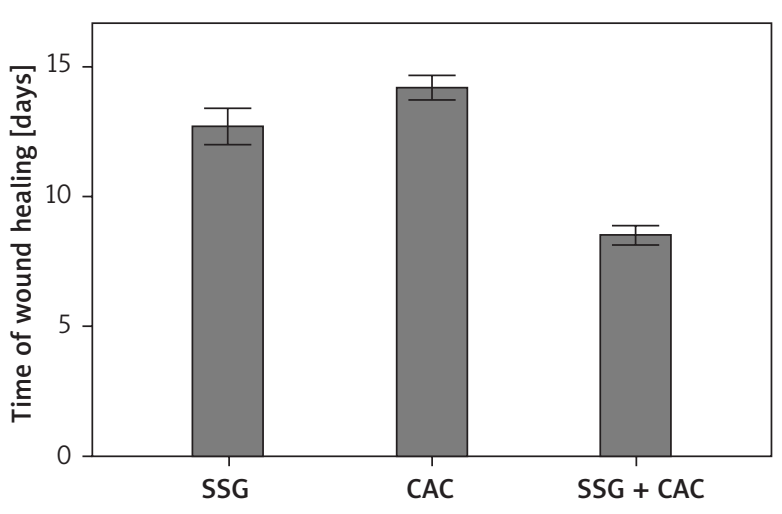

Figure 1. Mean time of wound healing in the analysed groups. Error bars represent standard error of the mean (SEM). Differences between SSG and CAC were not significant $(p=0.056)$, differences between SSG and SSG + CAC were significant $(p<0.001)$

technique", we observed or may suppose acceleration of this process. Looking at the data, analyzing the time to heal, it seems that SSG as a "gold standard" may be significantly improved as a method by the simultaneous addition of keratinocyte cell culture. The ability to use the cell cultured in such a short time, from the skin sample taken to the sufficient keratinocyte multiplication, improved the validity of the method.

Such a procedure reduces the healing time significantly. On the other hand, the use of cultured cells only (CAC) is associated with a non-significant delay in healing, which emphasizes the role of this technique in patients with limited donor sites, especially among chil-

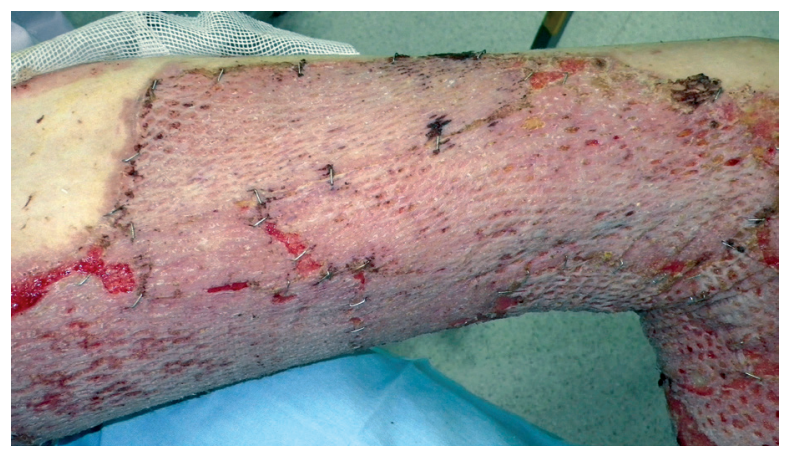

Figure 3. The condition 8 days later - the healing process completed 
dren. Because burn injury in children has an influence on the quality of the rest of the individual's life, it is so beneficial to improve the healing time and the treatment outcome. Additionally, we hope to achieve an improvement in the final late aesthetical result by the use of the "modified sandwich technique". The clue to the validity of this method is the significant improvement in the cell cultivation yielding such a large amount of cells over the course of a seven-day long cultivation period.

The basic rule in the local treatment of severe burns is the early excision of the necrotic tissue and the coverage of the skin defect as soon as possible [16]. It helps to avoid wound contamination. The presence of bacteria in the wound bed causes the main problem in local treatment, something independent of the way it is treated [3]. Severe burns result in changes in the balance between the endo - and exogenic microorganism [17].

During the first period, when the burn becomes merely contaminated or colonized, no signs of infection symptoms usually occur, although the balance between the microorganisms and the host is disturbed. This situation is still safe for a skin graft or cultured keratinocytes.

However, the state of colonization can change into critical colonization when microorganisms begin to grow rapidly and increase. Infection begins after the specific breakpoint of bacterial count per gram of tissue has been reached. The probability of the development of infection depends not only on the number of microorganisms, but also on the level of their activity, the age of the patient and coexisting diseases, the wound localization and size, and last but not least - on the presence of burn necrosis, being an ideal source of nutrients for microorganisms.

The majority of microorganisms that colonize and infect a burn wound are able to produce biofilm - the structure protecting bacteria from phagocytes, macrophages, antibodies and antibiotics [17].

According to many reports from specialized literature on the subject, tissue engineering has enabled the development of many advanced techniques that may accelerate wound closure, reduce the amount of donor skin, and allow for full-thickness skin reconstruction [1]. However, for each of these methods there are some pros and also cons, for example, the technical difficulties involved, or the question of a prohibitive price [4].

An analysis of the material presented in this report has shown a tendency for better wound healing, when we combine a typical meshed split-thickness skin graft with cultured autologous keratinocytes [18]. This technique seems to be very interesting for two reasons. One is the acceleration of wound closure, which minimizes the hospitalisation time and the number of medical procedures. The second reason is the improvement of the esthetical result. Extremely valuable for future analysis is also the recognition of the tendency for tissue contractures depending on the manner of wound closure. Enhanced acceleration of skin cell multiplication should be a scientific aim. However, the future should provide us with an alternative access to the materials or sources that could reduce the scaring process, so crucial in pediatric burns. The development of complex cell culture techniques together with/and three dimensional dermal substitutes (Living Skin Equivalents) are now great challenges for the surgeon and hope for the patient, leading us towards a solution of the basic task - complete, total true skin reconstruction.

\section{Conclusions}

To sum up, satisfaction with one's own activity, even in conditions of major limitations, allows for some degree of recompense for the impact of chronic illness on the functioning of a disabled person [19, 20].

\section{Acknowledgments}

This paper has been written entirely by the authors, and has received no external funding. The cost of the cell culture performed in the Laboratory of Cell and Tissue Engineering, Department of Cell Biology, Faculty of Biochemistry, Biophysics and Biotechnology, Jagiellonian University in Krakow was supported by the KBN/MNiSW grant 2008 (2009-2012) "The clinical application of autologous cell culture in burns with the use of Integra DRT - an analysis of the regeneration process in vitro".

The work was conducted in the Children's Burn Center at the University Children's Hospital in Krakow with which two authors: A. Chrapusta and M. Nessler, were affiliated until 2012.

\section{Conflict of interest}

The authors have no financial interests or other relating to this paper.

\section{References}

1. Heimbach D, Mann R, Engrav L. Evaluation of the burn wound. Management decisions. In: Total burn care. Herndon DN (ed.). W.B. Saunders Company Ltd, London 1996; 81-7.

2. Shakespeare PG. Standards and quality in burn treatment. Burns 2001; 27: 791-2.

3. Wach R, Chrapusta A. A new look at the role of ketamine in the treatment of burns - analysis of own experiences. Leczenie Ran 2012; 9: 153-6.

4. Horch RE, Kopp J, Knesser U, et al. Tissue engeenering of cultured skin substitutes. J Cell Mol Med 2005; 9: 592-608.

5. Ruberg RL. Clinics in plastic surgery. Advances in burn care. Vol. 13. W.B. Saunders Company, Philadelphia 1986.

6. Drewa T, Nadolski B, Czaplewski A, et al. Application of autologous and allogenic keratynocyte cultures in burn management. Przegl Lek 2005; 62: 934-7.

7. Krejci NC, Cuono CB, Langdon RC, et al. In vitro reconstitution of skin: fibroblasts facilitate keratinocyte growth and differentiation on acellular reticular dermis. J Invest Dermatol 1991; 97: 843-8. 
8. El-Ghalbzouri A, Gibbs S, Lamme E, et al. Effect of fibroblasts on epidermal regeneration. Br J Dermatol 2002; 147: 230-43.

9. Wood F, Kolybaba ML, Allen P. The use of cultured epithelial autograft in the treatment of major burn wounds. Eleven years of clinical experience. Burns 2006; 32: 538-44.

10. Phan TT, Lim IJ, Tan EK, et al. Evaluation of cell culture on the polyurethane-based membrane (Tegaderm): implication for tissue engineering of skin. Cell Tissue Bank 2005; 6: 91-7.

11. Matousková E, Broz L, Stolbová V, et al. Human allogeneic keratinocytes cultured on acellular xenodermis: the use in healing of burns and other skin defects. Biomed Mater Eng 2006; 16 (Suppl 4): S63-71.

12. Fujimori Y, Ueda K, Fumimoto H, et al. Skin regeneration for children with burn scar contracture using autologous cultured dermal substitutes and superthin auto-skin grafts: preliminary clinical study. Ann Plast Surg 2006; 57: 408-14.

13. El Ghalbzouri A, Ponec M. Diffusible factors released by fibroblasts support epidermal morphogenesis and deposition of basement membrane components. Wound Repair Regen 2004; 12: 359-67.

14. Gauglitz GG, Zedler S, von Spiegel F, et al. Functional characterization of cultured keratinocytes after acute cutaneous burn injury. PLOS ONE 2012; 7; e29942.

15. Loss M, Wedler V, Künzi W, et al. Artificial skin, split-thickness autograft and cultured autologous keratinocytes combined to treat a severe burn injury of $93 \%$ of TBSA. Burns 2000; 26: 644-52.

16. Sopata M, Tomaszewska E, Machyńska-Bućko Z, Kotlińska-Lemieszek A. Modern methods of conservative treatment of pressure ulcers. Postep Derm Alergol 2012; 29: 40-6.

17. Dowd SE, Sun Y, Secor PR, e al. Survey of bacterial diversity in chronic wounds using Pyrosequencing, DGGE, and full ribosome shotgun sequencing. BMC Microbiology 2008; 8: 4317.

18. Heng-yu L, Shi-chu X, Shi-hui Z, et al. Successful treatment of a patient with an extraordinarily large deep burn. Med Sci Monit 2011; 17: 47-51.

19. Tomaszewski W, Mańko G, Pachalska M, et al. Improvement of the Quality of Life of the persons with degenerative joint disease in the process of a comprehensive rehabilitation program enhanced by Tai Chi: the perspective of increasing therapeutic and rehabilitative effects through the applying of eastern techniques combining health-enhancing exercises and martial arts. Archives of Budo 2012; 7: 169-77.

20. Tomaszewski W, Mańko G, Ziółkowski A, et al. An evaluation of health-related quality of life of patients aroused from prolonged coma when treated by physiotherapists with or without training in the 'Academy of Life' programme. Ann Agric Environ Med 2013; 20: 319-23. 